\title{
Psychological Problems after Stroke and Their Management: State of Knowledge
}

\author{
Ian I. Kneebone ${ }^{1,2,3^{*}}$, Nadina B. Lincoln $^{4}$ \\ ${ }^{1}$ National Health Service of Great Britain and Northern Ireland (NHS) Improvement-Stroke Team, London, UK; ${ }^{2}$ Department of \\ Psychology, Surrey Community Health, Leatherhead, UK; ${ }^{3}$ Department of Psychology, University of Surrey, Guildford, UK; ${ }^{4}$ Institute \\ of Work Health and Organisations, University of Nottingham, Nottingham, UK. \\ Email: ${ }^{*}$ i.kneebone@nhs.net
}

Received December $17^{\text {th }}, 2011$; revised January $19^{\text {th }}, 2012$; accepted February $8^{\text {th }}, 2012$

\begin{abstract}
Background: Stroke has the greatest disabling impact of any chronic disease. Psychological changes including emotional, behavioural and cognitive changes can be common after stroke. Recently more attention has been given to these concerns. Content: This paper considers the nature of these problems, how they can be identified and the evidence for effective interventions. Conclusions: Research is needed into instruments to better identify anxiety after stroke and into treatments for emotional and behavioural changes. Further work is also needed to establish the best means for identifying cognitive deficits after stroke, particularly executive and memory problems, and into the optimal means of ameliorating these deficits.
\end{abstract}

Keywords: Stroke; Emotional Disturbances; Cognition Disorders; Therapy

\section{Introduction}

A stroke occurs when a blood clot or ruptured artery or blood vessel interrupts blood flow to an area of the brain. While around a third of those affected will die [1] for those who survive, the brain damage caused can result in multiple problems including impairments in speech, movement and cognition. In the UK around 150,000 people have a stroke each year and stroke is credited with having a greater disability impact than any other chronic disease [2]. The psychological sequelae to stroke include emotional and behavioural changes and cognitive impairment. Recently there has been increased recognition of these problems and directives to improve services that manage them [3]. A starting point to initiating these changes is an understanding of the nature of these problems, how to detect them and the evidence as to what might be effective interventions for them. This paper aims to provide such a foundation.

\section{Emotional and Behavioural Problems}

Table 1 lists emotional problems that can occur after stroke. Common problems include depression and anxiety. Emotional lability, a "catastrophic reaction", anger, aggression, frustration and apathy are also evident. Post-traumatic stress disorder and fear of falling are further concerns.

${ }^{*}$ Corresponding author.
Challenging behaviours are exhibited by some patients after stroke.

Depression occurs in approximately $30 \%$ of people post stroke [4]. It is distressing for the individual, and depression is associated with longer hospitalisation, institutionalisation, poorer functional outcome, and mortality [5-8]. Emotional lability or "involuntary emotional expression disorder" [9] refers to inappropriate or uncontrollable crying or laughing. Such reactions occur in $20 \%$ $-30 \%$ of stroke survivors $[10,11]$. A "catastrophic reaction" is an intense emotional reaction to the inability to

Table 1. Emotional problems after stroke.

\begin{tabular}{cc}
\hline Problem & Prevalence \\
\hline Depression & $30 \%[4]$ \\
Involuntary emotional expression disorder & $20 \%-30 \%[10,11]$ \\
Catastrophic reaction & $20 \%[12,13]$ \\
Appathy & $27 \%[16]$ \\
Generalised anxiety disorder & $22 \%-28 \%[17,18]$ \\
Post-traumatic stress reaction & $10 \%-30 \%[19-21]$ \\
Fear of falling & $60 \%[22]$ \\
Anger & $17 \%-35 \%[24-26]$ \\
\hline
\end{tabular}


perform tasks after neurological damage and occurs in up to $20 \%$ of stroke survivors $[12,13]$. Emotional lability and catastrophic reactions are often, but not always associated with depression. Apathy, a state in which patients demonstrate a lack of emotion, interest or concern [14] has been noted as a feature of depression after stroke [15] but may also present independently. It may be present in around $27 \%$ of people after they have had a stroke [16].

Anxiety disorders include generalised anxiety disorder, panic attacks, and post traumatic stress disorder. Some $22 \%$ to $28 \%$ of stroke patients are affected by generalised anxiety disorder $[17,18]$. The rate of panic disorder is not known. Post traumatic stress reactions appear in between $10 \%$ and $30 \%$ of patients $[19,21]$. Up to $60 \%$ of those with stroke can develop a fear of falling [22] and this has been associated with poorer physical function and a history of falls [23].

Many experience frustration after stroke. Anger after stroke ranges from irritability to verbal and physical aggression, and occurs in $17 \%-35 \%$ in the acute phase post stroke [24-26]. "Challenging behavioural problems" describe difficulties that encompass a wide range of behaviours that may be harmful to people or property, may be difficult to manage and may limit social access. They can include severe sexual disinhibition, shouting/screaming, and unrealistic demands for care/attention. There is no data on the prevalence of these problems after stroke.

\section{Identifying Emotional Problems}

Identifying emotional problems after stroke can be complicated by the overlap between the symptoms of stroke and symptoms of mental health disorders, as well as by impairment in cognitive and communication ability. Nonetheless there are several assessment measures available with identified cut offs for those with stroke, including for those with communication problems [27,28]. Most measures identify depression, but there are others that have been validated to identify anxiety and emotional lability. Measures able to identify anxiety in those with cognitive or communication problems are awaited. The benefit of standard assessments may lie in the fact that they provide a structured system whereby questions are asked about patients' emotional state, and pathways of action are provided to enable health care professionals to decide whom to refer for fuller evaluation. However, there is no evidence that screening leads to improved emotional outcomes.

\section{Treating Emotional Problems after Stroke}

\subsection{Depression and Associated Disorders}

Medication has a small but significant effect on depressive symptoms in stroke patients [29]. Medication treatment includes the SSRIs (Citalopram, Fluoxetine, and
Paroxetine), Nortriptyline, Amitriptyline, Deanxit, Aniracetam, Reboxetine, and Trazodone. Unfortunately, at present it is not possible to make statements as to whether one medication is more effective than another. A problem with treating depression after stroke with medication is the high rate of adverse events [29]. Studies with nonstroke samples indicate that the use of anti-depressants should be used reservedly for those with severe disorders [30,31].

In a Cochrane review Hackett et al. [29] considered the effect of psychotherapy on depressive symptoms after stroke and found no consistent evidence of benefit. However, there were very few studies of commonly provided interventions. There is limited support from research for the use of cognitive behaviour therapy [32,33], and counselling [34], and the findings of a randomised controlled trial of the former were not positive [35]. Evidence as to the effectiveness of other psychological therapies is restricted to single case study descriptions [36]. However, there is good support from a large number of studies in those without stroke, that psychological treatment is effective for depression [37,38].

Antidepressants for emotionalism reduce crying, with respect to both intensity and frequency, but there is no evidence to indicate the relative effectiveness of different classes of medication [39]. Sacco et al. [40] used a competing response/exposure paradigm to treat four patients with emotionalism and locked in syndrome after stroke, and all demonstrated some improvement. There is no literature on the treatment of apathy independent of depression after stroke.

\subsection{Treating Anxiety and Related Disorders after Stroke}

Only one trial of pharmacotherapy to treat anxiety after stroke has been reported, showing significant benefit [41]. Chinese studies have reported acupuncture [42] and slow stroke back massage reduce anxiety after stroke [43]. Cognitive behaviour therapy is highly effective for anxiety in older and working age people $[44,45]$, but remains to be evaluated in stroke survivors. Relaxation training is, as yet, unproven in a stroke sample. Supportive and psychodynamic approaches also await investigation [46].

To date there are no reports of pharmacological interventions in treating post traumatic stress after stroke. Antidepressants, particularly the SSRIs appear to be of benefit to those with PTSD without an identified stroke [47]. Trauma-focused cognitive behaviour therapy is also effective in treating post-traumatic stress in the general population [48], but remains to be investigated in those with stroke. Cognitive behavioural therapy [49], Tai chi, exercise and the use of hip protectors [50] have been found to reduce fear of falling but not specifically in those with stroke. 


\subsection{Treatment of Anger after Stroke}

Treatment of anger after stroke remains largely uninvestigated. Glancy and Knott [51] have broadly suggested medications for the treatment of anger. Meta-analyses have supported the use of psychological interventions to treat anger in adults, though none specific to those who have had a stroke. DeVecchio and O'Leary [52] concluded that for non-institutionalised adults CBT is useful for driving anger, anger suppression and trait anger. They recommend relaxation therapy for state anger.

\subsection{Treatment of Behavioural Problems}

The literature on interventions for behavioural problems after stroke is highly limited, however it is considered that behavioural management strategies involving functional analysis of the behaviour of concern may be effective [28]. As with other populations, the use of medications to manage challenging behavioural problems after stroke remains unproven.

\subsection{Prevention of Emotional Problems after Stroke}

There is no evidence of any benefit of anti-depressants in preventing the onset of depression after stroke [53]. However, there is some evidence to support the provision of psychological treatments [53]. Motivational interviewing and problem solving therapy appear to offer preventative effects in this regard after stroke. Other psychological interventions such as distress management, group support and music therapy have been provided, but the evidence is limited [28]. However, the provision of information to patients and carers, and planned follow ups do improve patients' mood [54].

\section{Cognitive Impairments after Stroke}

Cognitive impairments affect about $80 \%$ of stroke patients $[55,56]$. They are more common in the acute phase but many problems persist over time. Cognitive impairments are important because they are associated with rehabilitation outcome [56-59]. Impairments occur in cognitive domains, including attention, memory, language, visuospatial abilities, executive functions and praxis. In addition, there may be loss of awareness of deficits (anosognosia). Further, some patients have a dementia after stroke, usually vascular, which produces a progressive decline in cognitive abilities over time.

\section{Screening for Cognitive Impairments after Stroke}

Cognitive screening measures are used for two purposes, one is to detect post-stroke dementia and the other is to determine the pattern of cognitive impairments following stroke. Brief screening measures, derived from those used for the detection of Alzheimer's dementia have been shown to be poor at detecting post stroke dementia [28]. Some widely used measures, such as the Mini Mental State Examination-MMSE [60] do not perform any better than chance [61]. Others, such as the Montreal Cognitive Assessment-MOCATEST [62], include more tests of executive abilities, which tend to be the most frequently impaired in vascular dementias, and are more sensitive. However, there are few validation studies [63].

Screening measures have also been used to detect cognitive impairment after stroke. The application of screening batteries developed for people with dementia, such as the Middlesex Elderly Assessment of Mental State-MEAMS [64], have rarely been supported [65]. However, they were useful in a stepped screening model as they were more sensitive than the brief bedside measures. An alternative strategy to detect cognitive impairment after stroke seems to be to screen in specific cognitive domains. Tests have been identified to detect language impairment such as the Frenchay Aphasia Screening Test-FAST [66], and The Sheffield Screening Test for Acquired Language Disorders-SSTALD [67]. Visual inattention can be assessed using Star Cancellation [68] and visuospatial impairment using the Rey Figure Copy [69] and Ravens Matrices [70]. There are also valid tests for apraxia [71]. However, there is little evidence to support screening measures to detect impairments of memory and executive abilities after stroke. Screening measures should be used to identify people who need further evaluation as the challenge is to correctly identify those without cognitive problems rather than those with them. The suggestion is therefore that all patients are screened with a brief bedside screening during the acute phase. If there are concerns about whether patients have capacity, further evaluation may be needed [72]. Those with no detectable problems on these bedside screening measures should be further evaluated using more sensitive tests. Those who have no detectable problems on these may need further evaluation if they wish to return to cognitively demanding activities, such as work [73], and driving a car [74-76]. These patients will require a comprehensive or specialist neuropsychological assessment, usually once they have been discharged from hospital to the community. There is some evidence to suggest that cognitive assessment can reduce stress in carers [77].

\section{Cognitive Rehabilitation}

Cognitive rehabilitation is provided to reduce cognitive impairments after stroke and improve functional outcomes. Narrative reviews have suggested there is evidence to support the effectiveness of cognitive rehabilitation [78,79]. However, Cochrane reviews have identified a dearth of high quality studies. There is evidence that cognitive rehabilitation can reduce some cognitive impairments, such 
as visual inattention [80] after stroke but there is a lack of evidence for an effect on functional outcome. In addition, there is little evidence to support or refute the effectiveness of rehabilitation of memory [81], attention [82], or apraxia after stroke $[83,84]$. However, lack of evidence does not mean such procedures are ineffective, and there are ample single case experimental design studies to support the provision of cognitive rehabilitation. Therefore it is important that visual inattention is treated as part of a rehabilitation programme. Other cognitive problems will also need an individualised treatment plan, based on expert guidelines rather than strong research evidence.

\section{Research Needs}

Research is needed to identify better measures to screen for anxiety problems after stroke, in both those with and without communication/cognitive problems. The investigation for psychological means to both prevent and treat emotional problems after stroke is in its infancy, and much needs to be done. There are few randomised controlled trials of individual or group psychological interventions after stroke, despite the evidence of the effectiveness of these in the non-stroke population. The provision of information is one means of supporting mood. The nature, prevalence and best means for managing challenging behaviours after stroke should be documented.

Cognitive assessments need to be developed to identify people with impairment of memory and executive abilities after stroke. In particular screening measures need to be developed which are sensitive to vascular dementia. Cognitive rehabilitation programmes have been shown to improve outcomes in individual patients, but more evidence is needed to indicate the generalisability of these findings.

\section{Acknowledgements}

Andrew Bateman, Louise Clark, Sarah Gillham, and Allan House are all to be thanked for their helpful comments. This article is based on a paper commissioned by the NHS Stroke Improvement Programme, who financially supported open access publication.

\section{REFERENCES}

[1] P. Scarborough, et al., "Stroke Statistics 2009," University of Oxford, Oxford, 2009.

[2] C. Wolfe, T. Rudd and R. Beech, "Stroke Services and Research," The Stroke Association, London, 1996.

[3] Department of Health, "National Stroke Strategy," Department of Health, London, 2007.

[4] M. L. Hackett, C. Yapa, V. Parag and C. S. Anderson, "Frequency of Depression after Stroke: A Systematic Review of Observational Studies," Stroke, Vol. 36, 2005, pp. 1330-1340. doi:10.1161/01.STR.0000165928.19135.35
[5] N. Herrmann, S. E. Black, J. Lawrence, C. Szekely and J. P. Szalai, "The Sunnybrook Stroke Study: A Prospective Study of Depressive Symptoms and Functional Outcome," Stroke, Vol. 29, No. 3, 1998, pp. 618-624. doi:10.1161/01.STR.29.3.618

[6] A. House, P. Knapp, J. Bamford and A. Vail, "Mortality at 12 and 24 Months after Stroke May Be Associated with Depressive Symptoms at 1 Month," Stroke, Vol. 32, No. 3, 2001, pp. 696-701. doi:10.1161/01.STR.32.3.696

[7] P. L. Morris, R. G. Robinson, P. Andrzejewski, J. Samuels and T. R. Price, "Association of Depression with 10Year Poststroke Mortality," The American Journal of Psychiatry, Vol. 150, No. 1, 1993, pp. 124-129.

[8] T. Pohjasvaara, R. Vataja, A. Leppävuori, M. Kaste and T. Erkinjuntti, "Depression Is an Independent Predictor of Poor Long-Term Functional Outcome Post-Stroke," European Journal of Neurology, Vol. 8, No. 4, 2001, pp. 315-319. doi:10.1046/j.1468-1331.2001.00182.x

[9] J. L. Cummings, et al., "Defining and Diagnosing Involuntary Emotional Expression Disorder," CNS Spectrums, Vol. 11, No. 6, 2006, pp. 1-7.

[10] T. Calvert, P. Knapp and A. House, "Psychological Associations with Emotionalism after Stroke," Journal of Neurology, Neurosurgery, and Psychiatry, Vol. 65, No. 6, 1998, pp. 928-929. doi:10.1136/jnnp.65.6.928

[11] A. House, M. Dennis, A. Molyneux, C. Warlow and K. Hawton, "Emotionalism after Stroke," BMJ, Vol. 298, No. 6679, 1989, pp. 991-994. doi:10.1136/bmj.298.6679.991

[12] A. Carota, A. O. Rossetti, T. Karapanayiotides and J. Bogousslavsky, "Catastrophic Reaction in Acute Stroke: A Reflex Behavior in Aphasic Patients," Neurology, Vol. 57, No. 10, 2001, pp. 1902-1905.

[13] S. E. Starkstein, J. P. Fedoroff, T. R. Price, R. Leiguarda and R. G. Robinson, "Catastrophic Reaction after Cerebrovascular Lesions: Frequency, Correlates, and Validation of a Scale," The Journal of Neuropsychiatry and Clinical Neurosciences, Vol. 5, No. 2, 1993, pp. 189-194.

[14] R. S. Marin, "Differential Diagnosis and Classification of Apathy," The American Journal of Psychiatry, Vol. 147, No. 1, 1990, pp. 22-30.

[15] L. Caeiro, J. M. Ferro, C. O. Santos and M. L. Figueira, "Depression in Acute Stroke," Journal of Psychiatry \& Neuroscienc, Vol. 31, No. 6, 2006, pp. 377-383.

[16] P. Angelelli, et al., "Development of Neuropsychiatric Symptoms in Poststroke Patients: A Cross-Sectional Study," Acta Psychiatrica Scandinavica, Vol. 110, No. 1, 2004, pp. 55-63. doi:10.1111/j.1600-0447.2004.00297.x

[17] M. Aström, "Generalized Anxiety Disorder in Stroke Patients. A 3-Year Longitudinal Study," Stroke, Vol. 27, No. 2, 1996, pp. 270-275. doi:10.1161/01.STR.27.2.270

[18] L. De Wit, et al., "Motor and Functional Recovery after Stroke: A Comparison of 4 European Rehabilitation Centers," Stroke, Vol. 38, No. 7, 2007, pp. 2101-2107. doi:10.1161/STROKEAHA.107.482869

[19] L. Bruggimann, J. M. Annoni, F. Staub, N. von Steinbüchel, M. Van der Linden and J. Bogousslavsky, "Chronic Posttraumatic Stress Symptoms after Nonsevere Stroke," Neurology, Vol. 66, No. 4, 2006, pp. 513-516. 
doi:10.1212/01.wnl.0000194210.98757.49

[20] E. L. Field, P. Norman and J. Barton, "Cross-Sectional and Prospective Associations between Cognitive Appraisals and Posttraumatic Stress Disorder Symptoms Following Stroke," Behaviour Research and Therapy, Vol. 46, 2008, pp. 62-70. doi:10.1016/j.brat.2007.10.006

[21] S. Sembi, N. Tarrier, P. O’Neill, A. Burns and B. Faragher, "Does Post-Traumatic Stress Disorder Occur after Stroke: A Preliminary Study," International Journal of Geriatric Psychiatry, Vol. 13, No. 5, 1998, pp. 315-322. doi:10.1002/(SICI)1099-1166(199805)13:5<315::AID-G PS766>3.0.CO;2-P

[22] Y. Watanabe, "Fear of Falling among Stroke Survivors after Discharge from Inpatient Rehabilitation," International Journal of Rehabilitation Research, Vol. 28, No. 2, 2005, pp. 149-152. doi:10.1097/00004356-200506000-00008

[23] B. Belgen, M. Beninato, P. E. Sullivan and K. Narielwalla, "The association of Balance Capacity and Falls Self-Efficacy with History of Falling in CommunityDwelling People with Chronic Stroke," Archives of Physical Medicine and Rehabilitation, Vol. 87, No. 4, 2006, pp. 554-561. doi:10.1016/j.apmr.2005.12.027

[24] S. Aybek, et al., "Emotional Behavior in Acute Stroke: The Lausanne Emotion in Stroke study," Cognitive and Behavioral Neurology, Vol. 18, No. 1, 2005, pp. 37-44. doi:10.1097/01.wnn.0000152226.13001.8a

[25] C. O. Santos, L. Caeiro, J. M. Ferro, R. Albuquerque and M. Luísa Figueira, "Anger, Hostility and Aggression in the First Days of Acute Stroke," European Journal of Neurology, Vol. 13, No. 4, 2006, pp. 351-358. doi:10.1111/j.1468-1331.2006.01242.X

[26] J. S. Kim, S. Choi, S. U. Kwon and Y. S. Seo, "Inability to Control Anger or Aggression after Stroke," Neurology, Vol. 58, No. 7, 2002, pp. 1106-1108.

[27] H. E. Bennett and N. B. Lincoln, "Potential Screening Measures for Depression and Anxiety after Stroke," International Journal of Therapy and Rehabilitation, Vol. 13, No. 4, 2006, pp. 401-406.

[28] N. B. Lincoln, I. I. Kneebone, J. A. B. Macniven and R. C. Morris, "Psychological Management of Stroke," John Wiley \& Sons, Hoboken, 2012.

[29] M. L. Hackett, C. S. Anderson, A. O. House and J. Xia, "Interventions for Treating Depression after Stroke," Stroke, Vol. 40, 2009, pp. e487-e488.

[30] J. C. Fournier, et al., "Antidepressant Drug Effects and Depression Severity: A Patient-Level Meta-Analysis," The Journal of the American Medical Association, Vol. 303, No. 1, 2010, pp. 47-53. doi:10.1001/jama.2009.1943

[31] I. Kirsch, B. J. Deacon, T. B. Huedo-Medina, A. Scoboria, T. J. Moore and B. T. Johnson, "Initial Severity and Antidepressant Benefits: A Meta-Analysis of Data Submitted to the Food and Drug Administration," PLoS Medicine, Vol. 5, No. 2, 2008, p. e45. doi:10.1371/journal.pmed.0050045

[32] N. B. Lincoln, T. Flannaghan, L. Sutcliffe and L. Rother, "Evaluation of Cognitive Behavioural Treatment for Depression after Stroke: A Pilot Study," Clinical Rehabilita- tion, Vol. 11, No. 2, 1997, pp. 114-122. doi:10.1177/026921559701100204

[33] S. M. C. Rasquin, P. Van De Sande, A. J. Praamstra and C. M. Van Heugten, "Cognitive-Behavioural Intervention for Depression after Stroke: Five Single Case Studies on Effects and Feasibility," Neuropsychological Rehabilitation, Vol. 19, No. 2, 2009, pp. 208-222. doi:10.1080/09602010802091159

[34] A. Forster and J. Young, "Specialist Nurse Support for Patients with Stroke in the Community: A Randomised Controlled Trial," BMJ, Vol. 312, No. 7047, 1996, pp. 1642-1646. doi:10.1136/bmj.312.7047.1642

[35] N. B. Lincoln and T. Flannaghan, "Cognitive Behavioral Psychotherapy for Depression Following Stroke: A Randomized Controlled Trial," Stroke, Vol. 34, No. 1, 2003, pp. 111-115. doi:10.1161/01.STR.0000044167.44670.55

[36] I. I. Kneebone and E. Dunmore, "Psychological Management of Post-Stroke Depression," The British Journal of Clinical Psychology, Vol. 39, 2000, pp. 53-65. doi: $10.1348 / 014466500163103$

[37] P. Cuijpers, A. van Straten, A. van Schaik and G. Andersson, "Psychological Treatment of Depression in Primary Care: A Meta-Analysis," The British Journal of General Practic, Vol. 59, No. 559, 2009, pp. e51-60. doi:10.3399/bjgp09X395139

[38] K. C. M. Wilson, P. G. Mottram and C. A. Vassilas, "Psychotherapeutic Treatments for Older Depressed People," Cochrane Database of Systematic Reviews (Online), No. 1, 2008, p. CD004853.

[39] M. L. Hackett, M. Yang, C. S. Anderson, J. A. Horrocks and A. House, "Pharmaceutical Interventions for Emotionalism after Stroke," Cochrane Database of Systematic Reviews (Online), No. 2, 2010, p. CD003690.

[40] S. Sacco, M. Sarà, F. Pistoia, M. Conson, G. Albertini and A. Carolei, "Management of Pathologic Laughter and Crying in Patients with Locked-In Syndrome: A Report of 4 Cases," Archives of Physical Medicine and Rehabilitation, Vol. 89, 2008, pp. 775-778. doi:10.1016/j.apmr.2007.09.032

[41] E. Ohtomo, S. Hirai, A. Terashi and K. Araki, "Clinical Evaluation of Aniracetam on Psychiatric Symptoms Related to Cerebrovascular Disease," Journal of Clinical and Experimental Medicine, Vol. 156, 1991, pp. 143-187.

[42] P. Wu and S. Liu, "Clinical Observation on Post-Stroke Anxiety Neurosis Treated by Acupuncture," Journal of Traditional Chinese Medicine, Vol. 28, No. 3, 2008, pp. 186-188. doi:10.1016/S0254-6272(08)60043-6

[43] E. Mok and C. P. Woo, "The Effects of Slow-Stroke Back Massage on Anxiety and Shoulder Pain in Elderly Stroke Patients," Complementary Therapies in Nursing \& Midwifery, Vol. 10, No. 4, 2004, pp. 209-216. doi:10.1016/j.ctnm.2004.05.006

[44] C. R. Ayers, J. T. Sorrell, S. R. Thorp and J. L. Wetherell, "Evidence-Based Psychological Treatments for Late-Life Anxiety," Psychology and Aging, Vol. 22, No. 1, 2007, pp. 8-17. doi:10.1037/0882-7974.22.1.8

[45] A. C. Butler, J. E. Chapman, E. M. Forman and A. T. Beck, "The Empirical Status of Cognitive-Behavioral The- 
rapy: A Review of Meta-Analyses," Clinical Psychology Review, Vol. 26, No. 1, 2006, pp. 17-31. doi:10.1016/j.cpr.2005.07.003

[46] V. Hunot, R. Churchill, M. Silva de Lima and V. Teixeira, "Psychological Therapies for Generalised Anxiety Disorder," Cochrane Database of Systematic Reviews (Online), No. 1, 2007, p. CD001848.

[47] D. J. Stein, J. C. Ipser and S. Seedat, "Pharmacotherapy for Post Traumatic Stress Disorder (PTSD)," Cochrane Database of Systematic Reviews (Online), No. 1, 2006, p. CD002795.

[48] J. Bisson and M. Andrew, "Psychological Treatment of post-Traumatic Stress Disorder (PTSD)," Cochrane Database of Systematic Reviews (Online), No. 3, 2007, p. CD003388.

[49] S. Tennstedt, J. Howland, M. Lachman, E. Peterson, L. Kasten and A. Jette, "A Randomized, Controlled Trial of a Group Intervention to Reduce Fear of Falling and Associated Activity Restriction in Older Adults," The Journals of Gerontology. Series B, Psychological Sciences and Social Sciences, Vol. 53, No. 6, 1998, pp. 384-392. doi:10.1093/geronb/53B.6.P384

[50] G. A. R. Zijlstra, J. C. M. van Haastregt, E. van Rossum, J. T. M. van Eijk, L. Yardley and G. I. J. M. Kempen, "Interventions to Reduce Fear of Falling in CommunityLiving Older People: A Systematic Review," Journal of the American Geriatrics Society, Vol. 55, No. 4, 2007, pp. 603-615. doi:10.1111/j.1532-5415.2007.01148.x

[51] G. D. Glancy and T. F. Knott, "Part III: The Psychopharmacology of Long Term Aggression-Towards an Evidences Based Algorithm," Canadian Psychiatric Association Bulletin, 2003, pp. 13-18.

[52] T. Del Vecchio and K. D. O'Leary, "Effectiveness of Anger Treatments for Specific Anger Problems: A MetaAnalytic Review," Clinical Psychology Review, Vol. 24, No. 1, 2004, pp. 15-34. doi:10.1016/j.cpr.2003.09.006

[53] M. L. Hackett, C. S. Anderson, A. House and C. Halteh, "Interventions for preventing depression after stroke," Cochrane Database of Systematic Reviews (Online), No. 3, 2008, p. CD003689.

[54] J. Smith, A. Forster, A. House, P. Knapp, J. Wright and J. Young, "Information Provision for Stroke Patients and Their Caregivers," Cochrane Database of Systematic Reviews (Online), No. 2, 2008, p. CD001919.

[55] G. M. S. Nys, M. J. E. van Zandvoort, P. L. M. de Kort, B. P. W. Jansen, E. H. F. de Haan and L. J. Kappelle, "Cognitive Disorders in Acute Stroke: Prevalence and Clinical Determinants," Cerebrovascular Diseases, Vol. 23, No. 5-6, 2007, pp. 408-416. doi:10.1159/000101464

[56] M. Leśniak, T. Bak, W. Czepiel, J. Seniów and A. Członkowska, "Frequency and Prognostic Value of Cognitive Disorders in Stroke Patients," Dementia and Geriatric Cognitive Disorders, Vol. 26, No. 4, 2008, pp. 356-363. doi: $10.1159 / 000162262$

[57] J. B. Hochstenbach, P. G. Anderson, J. van Limbeek and T. T. Mulder, "Is There a Relation between Neuropsychologic Variables and Quality of Life after Stroke?," Archives of Physical Medicine and Rehabilitation, Vol. 82, No. 10, 2001, pp. 1360-1366. doi:10.1053/apmr.2001.25970

[58] M. Hommel, S. T. Miguel, B. Naegele, N. Gonnet and A. Jaillard, "Cognitive Determinants of Social Functioning after a First Ever Mild to Moderate Stroke at Vocational Age," Journal of Neurology, Neurosurgery, and Psychiatry, Vol. 80, No. 8, 2009, pp. 876-880. doi:10.1136/jnnp.2008.169672

[59] G. M. S. Nys, et al., "The Prognostic Value of Domainspecific Cognitive Abilities in Acute First-Ever Stroke," Neurology, Vol. 64, No. 5, 2005, pp. 821-827. doi:10.1212/01.WNL.0000152984.28420.5A

[60] M. F. Folstein, S. E. Folstein and P. R. McHugh, “"Minimental State'. A Practical Method for Grading the Cognitive State of Patients for the Clinician," Journal of Psychiatric Research, Vol. 12, No. 3, 1975, pp. 189-198. doi:10.1016/0022-3956(75)90026-6

[61] V. Srikanth, et al., "The Validity of Brief Screening Cognitive Instruments in the Diagnosis of Cognitive Impairment and Dementia after First-Ever Stroke," International Psychogeriatrics, Vol. 18, No. 2, 2006, pp. 295-305. doi:10.1017/S1041610205002711

[62] Z. S. Nasreddine, et al., "The Montreal Cognitive Assessment, MoCA: A Brief Screening Tool for Mild Cognitive Impairment," Journal of the American Geriatrics Society, Vol. 53, No. 4, 2005, pp. 695-699. doi:10.1111/j.1532-5415.2005.53221.x

[63] S. T. Pendlebury, F. C. Cuthbertson, S. J. V. Welch, Z. Mehta and P. M. Rothwell, "Underestimation of Cognitive Impairment by Mini-Mental State Examination versus the Montreal Cognitive Assessment in Patients with Transient Ischemic Attack and Stroke: A PopulationBased Study," Stroke, Vol. 41, No. 6, 2010, pp. 12901293. doi:10.1161/STROKEAHA.110.579888

[64] E. Golding, "Middlesex Elderly Assessment of Mental State," Thames Valley Test Company, Sullfolk, 1989.

[65] A. Cartoni and N. B. Lincoln, "The Sensitivity and Specificity of the Middlesex Elderly Assessment of Mental State (MEAMS) for Detecting Cognitive Impairment after Stroke," Neuropsychological Rehabilitation, Vol. 15, No. 1, 2005, pp. 55-67. doi:10.1080/09602010443000029

[66] P. M. Enderby, V. Wood and D. Wade, "Frenchay Aphasia Screening Tes," Whurr Publishers, Oxford, 1997.

[67] D. Syder, R. Body, M. Parker and M. Boddy, "Sheffield Screening Test for Acquired Language Disorders," NFER Nelson, Slough, 1993.

[68] T. Manly, et al., "Assessment of Unilateral Spatial Neglect: Scoring Star Cancellation Performance from Video Recordings-Method, Reliability, Benefits, and Normative Data," Neuropsychology, Vol. 23, No. 4, 2009, pp. 519-528. doi:10.1037/a0015413

[69] A. Rey, "Le Test de Copie de Figure Complexe," Journals of Gerontology, Vol. 38, 1959, pp. 344-348.

[70] J. Raven, "Manual for Raven's Progressive Matrices and Vocabulary Scales," Oxford Psychologists Press, Oxford, 1989.

[71] C. M. van Heugten, J. Dekker, B. G. Deelman, F. C. Stehmann-Saris and A. Kinebanian, "A Diagnostic Test for Apraxia in Stroke Patients: Internal Consistency and 
Diagnostic Value," The Clinical Neuropsychologist, Vol. 13, No. 2, 1999, pp. 182-192.

doi:10.1076/clin.13.2.182.1966

[72] J. Moye and D. C. Marson, "Assessment of DecisionMaking Capacity in Older Adults: An Emerging Area of Practice and Research," The Journals of Gerontology. Series $B$, Psychological Sciences and Social Sciences, Vol. 62, No. 1, 2007, pp. 3-11. doi:10.1093/geronb/62.1.P3

[73] S. Saeki, "Disability Management after Stroke: Its Medical Aspects for Workplace Accommodation," Disability and Rehabilitation, Vol. 22, No. 13-14, 2000, pp. 578582. doi:10.1080/09638280050138241

[74] F. M. Nouri and N. B. Lincoln, "Predicting Driving Performance after Stroke," BMJ, Vol. 307, No. 6902, 1993, pp. 482-483. doi:10.1136/bmj.307.6902.482

[75] A. E. Akinwuntan, H. Feys, W. De Weerdt, G. Baten, P. Arno and C. Kiekens, "Prediction of Driving after Stroke: a Prospective Study," Neurorehabilitation and Neural Repair, Vol. 20, No. 3, 2006, pp. 417-423. doi:10.1177/1545968306287157

[76] S. George and M. Crotty, "Establishing Criterion Validity of the Useful Field of View Assessment and Stroke Drivers' Screening Assessment: Comparison to the Result of On-Road Assessment," The American Journal of Occupational Therapy, Vol. 64, No. 1, 2010, pp. 114-122. doi:10.5014/ajot.64.1.114

[77] M. McKinney, H. Blake, K. A. Treece, N. B. Lincoln, E. D. Playford and J. R. F. Gladman, "Evaluation of Cognitive Assessment in Stroke Rehabilitation," Clinical Rehabilitation, Vol. 16, No. 2, 2002, pp. 129-136. doi:10.1191/0269215502cr479oa

[78] K. D. Cicerone, et al., "Evidence-Based Cognitive Rehabilitation: Updated Review of the Literature from 1998 through 2002," Archives of Physical Medicine and Rehabilitation, Vol. 86, No. 8, 2005, pp. 1681-1692. doi:10.1016/j.apmr.2005.03.024

[79] T. Manly, "Cognitive Rehabilitation for Unilateral Neglect: Review," Neuropsychological Rehabilitation, Vol. 12, 2002, pp. 289-310. doi:10.1080/0960201044000101

[80] A. Bowen and N. B. Lincoln, "Cognitive Rehabilitation for Spatial Neglect Following Stroke," Cochrane Database of Systematic Reviews (Online), No. 2, 2007, p. CD003586.

[81] R. D. das Nair and N. B. Lincoln, "Cognitive Rehabilitation for Memory Deficits Following Stroke," Cochrane Database of Systematic Reviews (Online), No. 3, 2007, p. CD002293.

[82] N. B. Lincoln, M. J. Majid and N. Weyman, "Cognitive Rehabilitation for Attention Deficits Following Stroke," Cochrane Database of Systematic Reviews (Online), No. 4, 2000, p. CD002842.

[83] C. West, A. Bowen, A. Hesketh and A. Vail, "Interventions for Motor Apraxia Following Stroke," Cochrane Database of Systematic Reviews (Online), No. 1, 2008, p. CD004132.

[84] C. West, A. Hesketh, A. Vail and A. Bowen, "Interventions for Apraxia of Speech Following Stroke," Cochrane Database of Systematic Reviews (Online), No. 4, 2005, p. CD004298. 